\title{
Adverse Effects of Preoperative Sarcopenia on Postoperative Complications of Patients With Gastric Cancer
}

\author{
TATSURO TAMURA ${ }^{1}$, KATSUNOBU SAKURAI $^{2}$, MIKIO NAMBARA $^{1}$, \\ YUICHIRO MIKI ${ }^{1}$, TAKAHIRO TOYOKAWA ${ }^{1}$, NAOSHI KUBO ${ }^{2}$, HIROAKI TANAKA ${ }^{1}$, \\ KAZUYA MUGURUMA ${ }^{1}$, MASAKAZU YASHIRO ${ }^{1}$ and MASAICHI OHIRA ${ }^{1}$ \\ ${ }^{1}$ Department of Gastroenterological Surgery, Osaka City University, Graduate School of Medicine, Osaka, Japan; \\ ${ }^{2}$ Department of Gastroenterological Surgery, Osaka City General Hospital, Osaka, Japan
}

\begin{abstract}
Background: Sarcopenia is known to have an important influence on postoperative complications in several diseases, and on the prognosis of patients with cancer. However, whether sarcopenia is associated with complications and prognosis after gastrectomy in patients with gastric cancer remains controversial. This study evaluated the impact of the preoperative muscle mass on postoperative complications of gastric cancer surgery. Materials and Methods: The muscle mass of 153 patients who underwent gastrectomy for gastric cancer from January 2014 to August 2016 was assessed before surgery by a multifrequency bioelectrical impedance analysis (In Body 3.0; Biospace, Tokyo, Japan) and was expressed as the muscle mass index (MMI). Sarcopenia was defined as an MMI value of one standard deviation or more below the gender-specific mean MMI. Complications of Clavien-Dindo grade 2 or more were defined as significant postoperative complications. The impact of preoperative sarcopenia on postoperative infectious complications was analyzed by univariate and multivariate analyses. Results: A total of 153 patients were analyzed, sarcopenia was present in 24 out of 153 patients (15.7\%). Thirty (19.6\%) patients developed postoperative complications, 20 (13.1\%) of which were infectious complications. Sarcopenia was significantly associated with age, body mass index, serum albumin, pulmonary disease in comorbidities, operative time, surgical approach, and postoperative complications. The univariate analyses revealed that male sex, sarcopenia, total gastrectomy, laparotomy, and intraoperative blood loss were associated with postoperative infectious complications. In the multivariate analyses,
\end{abstract}

Correspondence to: Tatsuro Tamura, 1-4-3 Asahi-machi, Abeno-ku, Osaka 545-8585, Japan. Tel: +81 666453838, Fax: +81666466450 e-mail: tamura.tatsuro@med.osaka-cu.ac.jp

Key Words: Muscle mass, sarcopenia, gastric cancer, postoperative complication. sarcopenia and intraoperative blood loss $\geq 400 \mathrm{ml}$ were independently associated with postoperative infectious complications. Conclusion: Preoperative sarcopenia was found to be an independent risk factor for postoperative infectious complications in gastric cancer patients.

Despite recent advances in surgical procedures and perioperative management techniques, postoperative complications sometimes occur after gastrectomy in patients with gastric cancer. Several factors, such as older age and a low nutrition status, have been identified as risk factors for postoperative complications of gastric cancer surgery.

Sarcopenia, a newly identified marker of frailty, is characterized by decreased muscle mass and a low muscle strength and function by the European Working Group on Sarcopenia in Older People (EWGSOP) (1). Sarcopenia is known to have an important influence on postoperative complications in several diseases (2-9) and on the prognosis of patients with cancer $(2,10-12)$.

Bioelectrical impedance analysis (BIA) is a safe, easy and non-invasive method for evaluating body composition (13, 14). The measurement of body composition by BIA is reported to be useful for evaluating the preoperative nutritional status of patients and in predicting outcomes $(5,15)$. However, few studies have evaluated the association between the preoperative muscle mass, as measured by a BIA, and the perioperative outcomes of patients with gastric cancer.

The aim of this study was to examine the utility of determination of sarcopenia, as evaluated by BIA, in predicting postoperative complications among patients undergoing gastrectomy for gastric cancer.

\section{Materials and Methods}

Patients. A total of 202 consecutive patients underwent gastrectomy for gastric cancer at the Department of Gastroenterological Surgery, Osaka City University between April 2014 and August 2016. Five patients with remnant gastric cancer, nine patients who underwent R2 resection, and 35 patients for whom there were no muscle mass 
data were excluded from the analysis. Finally, 153 patients were enrolled in this study (Figure 1). Tumors were histologically diagnosed based on the Japanese Classification of Gastric Carcinoma, 14th edition (16)

Assessment of sarcopenia. The body composition was assessed before gastrectomy by multifrequency BIA (InBody 3.0; Biospace, Tokyo, Japan). The muscle mass was converted to the muscle mass index (MMI) by dividing the patient's muscle mass by their height squared $\left(\mathrm{kg} / \mathrm{m}^{2}\right)$. Sarcopenia was defined as an MMI value of one standard deviation below the gender-specific mean MMI based on previously published studies (17).

Treatment strategy. All patients were managed routinely according to the Japanese Gastric Cancer Treatment Guidelines, 2010 (version 3) (18). Laparoscopic gastrectomy was performed in patients who fulfilled the two following criteria: $\leq \mathrm{cT} 2$, and $\leq \mathrm{cN} 1$. Other patients underwent gastrectomy by laparotomy.

Evaluation of outcome. Postoperative complications that developed within 30 days after gastrectomy were evaluated. In this study, postoperative complications were classified as infectious or noninfectious complications, and were evaluated according to the Clavien-Dindo (CD) classification (19). We defined postoperative complications as $\mathrm{CD}$ grade 2 or more. Pancreatic fistula was defined according to the International Study Group on Pancreatic Fistula definition (20): output via an operatively placed drain of any measurable volume of drain fluid on or after postoperative day 3 , with an amylase content more than three times higher than the upper normal serum value.

Statistical analysis. All statistical analyses were performed using JMP program (SAS Institute, Cary, NC, USA). Fisher's exact test and the chi-squared test were used to compare categorical variables, and the Wilcoxon test was used to compare continuous variables. Postoperative complications were examined by univariate and multivariate logistic regression analysis. $p$-Values of less than 0.05 were considered to indicate statistically significant differences.

\section{Results}

The distribution of MMI is shown in Figure 2. In men and women, the mean values (one standard deviation) are 17.15 (1.71), and 14.56 (1.23), respectively. Thus, the cut-off points were $15.44 \mathrm{~kg} / \mathrm{m}^{2}$ (men) and $13.33 \mathrm{~kg} / \mathrm{m}^{2}$. Patients with low and high MMI values were classified into groups with and without sarcopenia, respectively. Twenty-four patients were classified into the sarcopenic group (17 males; seven females).

A summary of patient characteristics is shown in Table I. The group with sarcopenia was significantly older than the group without (74 vs. 68 years, respectively; $p=0.023$ ). The body composition analysis revealed that the BMI and MMI values of the group with sarcopenia were significantly lower than those without (17.9 vs. $22.6 \mathrm{~kg} / \mathrm{m}^{2}$ and 14.5 vs. $16.8 \mathrm{~kg} / \mathrm{m}^{2}$, respectively; both $p<0.001)$. Regarding the nutritional status, the serum albumin level of the group without sarcopenia was significantly higher than that of sarcopenic group (3.8 vs. $4 \mathrm{~g} / \mathrm{dl}$;

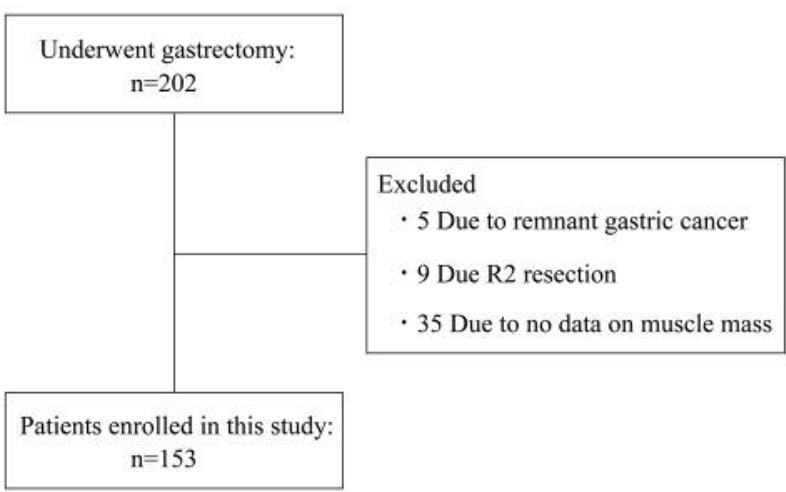

Figure 1. The patient selection process followed in this study.

$p=0.037$ ). The levels of C-reactive protein (a marker of systemic inflammation) of the two groups were similar (sarcopenia $v s$. non-sarcopenia: $0.05 v s .0 .08 \mathrm{mg} / \mathrm{dl}$; $p=0.446$ ). The American Society of Anesthesiologists physical status (ASA-PS) of the two groups did not differ to a statistically significant extent $(p=0.312)$. Regarding comorbidities, the incidence of pulmonary disease was significantly higher in the group with sarcopenia $(p=0.028)$, while the incidence of other comorbidities did not differ statistically significantly. The clinical TNM stage, which reflects clinical cancer progression, did not differ to a statistically significant extent $(p=0.556)$.

As shown in Table II, there was no significant difference in the type of surgery; however, the rate of laparotomy in the group with sarcopenia was significantly higher than that in the group without (70.8 vs. $44.2 \%$; $p=0.015)$. The higher number of cT3 or 4 cases in the group with sarcopenia may have accounted for this difference. The operative times and blood loss of the two groups did not differ to a statistically significant extent. Grade 2 or more postoperative complications occurred significantly more frequently in the group with sarcopenia (37.5 vs. $16.3 \%$, respectively; $p=0.024$ ). When postoperative complications were classified as infectious or non-infectious, infectious complications occurred significantly more frequently in the group with sarcopenia (29.2 vs. 10\%, respectively; $p=0.021$ ), while the incidence of non-infectious complications did not differ to a statistically significant extent (8.4 vs. $6.2 \%$, respectively; $p=0.707)$. To further analyze the association between sarcopenia and postoperative complications, we investigated risk factors for postoperative infectious complications. The results of the univariate and multivariate analyses of factors associated with postoperative infectious complications (grade 2 or more) are shown in Table III. In the univariate analysis, male sex [odds ratio $(\mathrm{OR})=5.421$, $p=0.008)]$, sarcopenia $(\mathrm{OR}=3.674, p=0.021)$, total gastrectomy $(\mathrm{OR}=3.586, p=0.011)$, laparotomy $(\mathrm{OR}=2.839, p=0.036)$, and intraoperative blood loss $(\mathrm{OR}=7.552, p<0.001)$ were associated 

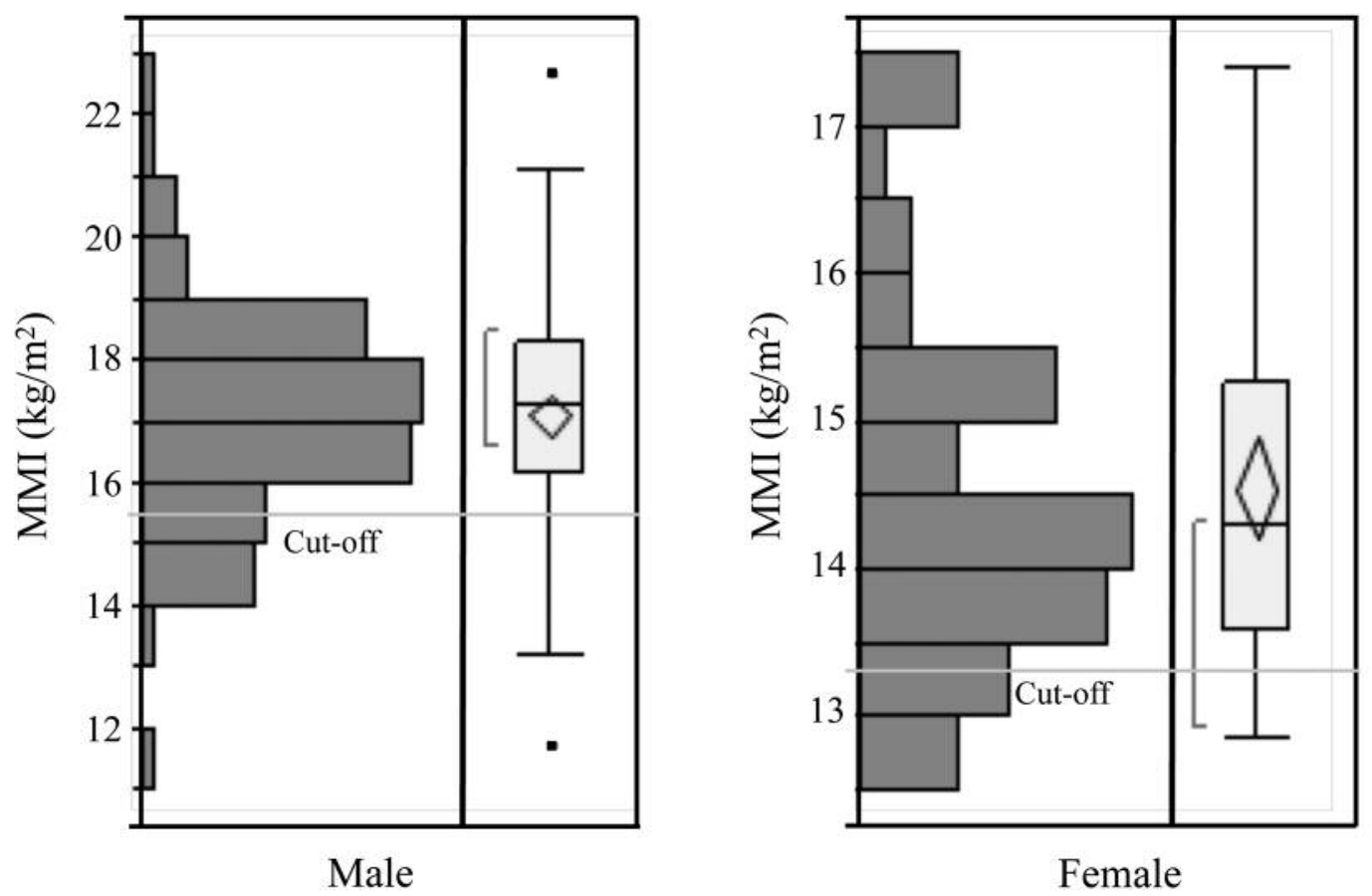

Figure 2. The distribution of muscle mass index (MMI) values and box plot according to gender. Each horizontal line shows the cut-off for sarcopenia.

with postoperative infectious complications. In the multivariate analysis, sarcopenia $(\mathrm{OR}=4.358, p=0.024)$ and intraoperative blood loss $(\mathrm{OR}=6.151, p=0.006)$ were independently associated with postoperative infectious complications.

\section{Discussion}

Surgery is the most important curative treatment for gastric cancer other than early-stage gastric cancer, for which endoscopic treatment is indicated. Despite recent advances in surgical procedures and perioperative management techniques, postoperative complications sometimes occur after gastrectomy in patients with gastric cancer. Postoperative complications impair healthy lifestyles, increase healthcare costs, and may diminish adherence to postoperative treatment, which results in poorer oncological outcomes (21). Several factors, such as comorbidities, older age, poor activities of daily living, and obesity are generally identified as risk factors for postoperative complications after gastric cancer surgery. However, there is no reliable evidence to support that any of these are risk factors for postoperative complications, and no definite consensus has been achieved. Sarcopenia is characterized by decreased muscle mass, and low muscle strength and function (1). It was found to be associated with postoperative complications after surgery for esophageal (5, $6)$, colorectal (3), pancreatic $(4,7)$, hepatocellular $(2,8)$, and metastatic liver cancer (9). In this study, we demonstrated that muscle mass, one of the elements of sarcopenia, is a risk factor for postoperative infectious complications after surgery for gastric cancer.

Various methods have been used to analyze muscle, including BIA, dual-energy X-ray absorptiometry, and crosssectional computed tomography (CT)-based muscle assessment. Mourtzakis et al. reported that the crosssectional area of the psoas muscle at the level of the third lumbar vertebra was directly correlated with the whole-body skeletal muscle mass in patients with cancer (22). CT is regularly conducted before surgery for the clinical staging of gastric cancer; thus, the psoas muscle may be assessed by this method without an undue burden on patients. For this reason, $\mathrm{CT}$ imaging has been the modality most frequently used to predict preoperative sarcopenia and investigate the relationship between sarcopenia and postoperative outcomes. However, it is controversial whether the cross-sectional area of the intestinal psoas muscle at the third lumbar level truly reflects the whole-body muscle mass. On the other hand, BIA is not routinely performed as a preoperative examination; however, it is free from radiation exposure and is inexpensive and convenient to perform. In addition, BIA is a safe, non-invasive method that can be performed repeatedly to evaluate body composition. Furthermore, Kaido et al. who demonstrated that BIA enables the accurate 
Table I. Summary of patient characteristics $(n=153)$.

\begin{tabular}{|c|c|c|c|}
\hline Variable & $\begin{array}{l}\text { Sarcopenia } \\
\quad(\mathrm{n}=24)\end{array}$ & $\begin{array}{l}\text { Non sarcopenia } \\
\quad(\mathrm{n}=129)\end{array}$ & $p$-Value \\
\hline \multicolumn{4}{|l|}{ Age, years } \\
\hline Median (range) & $74(38-83)$ & $68(32-83)$ & 0.023 \\
\hline \multicolumn{4}{|l|}{ Gender, n (\%) } \\
\hline Male & $17(70.8)$ & $84(65.1)$ & \multirow[t]{2}{*}{0.583} \\
\hline Female & $7(29.2)$ & $45(34.9)$ & \\
\hline \multicolumn{4}{|l|}{ Body mass index, $\mathrm{kg} / \mathrm{m}^{2}$} \\
\hline Median (range) & $17.9(13.4-23)$ & $22.6(15.7-33.4)$ & $<0.001$ \\
\hline \multicolumn{4}{|c|}{ Muscle mass index, $\mathrm{kg} / \mathrm{m}^{2}$} \\
\hline Median (range) & $14.5(11.7-15.4)$ & $16.8(13.3-22.7)$ & $<0.001$ \\
\hline \multicolumn{4}{|l|}{ Serum albumin, $\mathrm{g} / \mathrm{dl}$} \\
\hline Median (range) & $3.8(2.9-4.5)$ & $4(1.8-5)$ & 0.037 \\
\hline \multicolumn{4}{|l|}{$\mathrm{CRP}, \mathrm{mg} / \mathrm{dl}$} \\
\hline Median (range) & $0.045(0.01-2.21)$ & $0.08(0.01-3.96)$ & 0.446 \\
\hline \multicolumn{4}{|l|}{ ASA-PS, n (\%) } \\
\hline 1 & $2(8.3)$ & $17(13.2)$ & \multirow[t]{3}{*}{0.312} \\
\hline 2 & $18(75)$ & $103(79.8)$ & \\
\hline 3 & $4(16.7)$ & $9(7)$ & \\
\hline \multicolumn{4}{|l|}{ Comorbidity, n (\%) } \\
\hline Pulmonary disease & $7(29.2)$ & $14(10.9)$ & 0.028 \\
\hline Cardiovascular disease & $3(12.5)$ & $6(4.7)$ & 0.175 \\
\hline Liver disease & $1(4.2)$ & $10(7.7)$ & 0.433 \\
\hline Renal disease & 0 & $4(3.1)$ & 0.239 \\
\hline Cerebrovascular disease & $4(16.7)$ & $14(10.9)$ & 0.436 \\
\hline Diabetes melitus & $2(8.3)$ & $22(17)$ & 0.249 \\
\hline \multicolumn{4}{|l|}{ Histology, n (\%) } \\
\hline Differentiated & $12(50)$ & $75(58.1)$ & \multirow[t]{2}{*}{0.461} \\
\hline Undifferentiated & $12(50)$ & $54(41.9)$ & \\
\hline \multicolumn{4}{|l|}{$\mathrm{cT}, \mathrm{n}(\%)$} \\
\hline $\mathrm{cT} 1$ & $9(37.5)$ & $63(48.8)$ & \multirow[t]{4}{*}{0.41} \\
\hline cT2 & $3(12.5)$ & $21(16.2)$ & \\
\hline cT3 & $9(37.5)$ & $27(20.1)$ & \\
\hline $\mathrm{cT} 4$ & $3(12.5)$ & 18 (13.9) & \\
\hline \multicolumn{4}{|l|}{$\mathrm{cN}, \mathrm{n}(\%)$} \\
\hline cNO & $12(50)$ & $78(60.5)$ & \multirow[t]{4}{*}{0.809} \\
\hline $\mathrm{cN} 1$ & $4(16.7)$ & $16(12.4)$ & \\
\hline $\mathrm{cN} 2$ & $4(16.7)$ & $16(12.4)$ & \\
\hline $\mathrm{cN} 3$ & $4(16.7)$ & $19(14.7)$ & \\
\hline \multicolumn{4}{|l|}{ cStage, n (\%) } \\
\hline $\mathrm{I}$ & $10(41.7)$ & $74(57.4)$ & \multirow[t]{4}{*}{0.556} \\
\hline II & $6(25)$ & $22(17.1)$ & \\
\hline III & $7(29.2)$ & $28(21.7)$ & \\
\hline IV & $1(4.1)$ & $5(3.8)$ & \\
\hline
\end{tabular}

ASA-PS: American Society of Anesthesiologists physical status; CRP: C-reactive protein.

measurement of the skeletal muscle mass without being influenced by edema or ascites in patients with chronic hepatitis, considered BIA to be the gold standard for assessing sarcopenia (23). However, there have been few studies on the use of BIA methods in the evaluation of patients with gastric cancer for sarcopenia. Thus, we selected a BIA method for the present study.

Sarcopenia was originally considered to be decreased muscle mass which occurs in association with aging, chronic
Table II. Perioperative data for 153 patients with gastric cancer according to sarcopenia status.

\begin{tabular}{|c|c|c|c|}
\hline Variable & $\begin{array}{l}\text { Sarcopenia } \\
\quad(\mathrm{n}=24)\end{array}$ & $\begin{array}{l}\text { Non sarcopenia } \\
\quad(\mathrm{n}=129)\end{array}$ & $p$-Value \\
\hline \multicolumn{4}{|l|}{ Type of surgery } \\
\hline $\mathrm{TG}, \mathrm{n}(\%)$ & $7(29.2)$ & $32(24.8)$ & 0.77 \\
\hline $\mathrm{DG}, \mathrm{n}(\%)$ & $17(70.8)$ & $96(74.4)$ & \\
\hline PG, n (\%) & 0 & $1(0.8)$ & \\
\hline \multicolumn{4}{|l|}{ Approach of surgery } \\
\hline Laparotomy, n (\%) & $17(70.8)$ & $57(44.2)$ & 0.015 \\
\hline Laparoscopy, n (\%) & $7(29.2)$ & $72(55.8)$ & \\
\hline \multicolumn{4}{|l|}{ Operative times, $\min$} \\
\hline Median (range) & $236(138-385)$ & $251(85-483)$ & 0.056 \\
\hline $\begin{array}{l}\text { Intraoperative blood loss, ml } \\
\text { Median (range) }\end{array}$ & $100(5-2390)$ & $100(0-1880)$ & 0.735 \\
\hline \multicolumn{4}{|l|}{$\begin{array}{l}\text { Postoperative } \\
\text { complications, n (\%) }\end{array}$} \\
\hline Infectious complications & $9(37.5)$ & $21(16.3)$ & 0.024 \\
\hline Total & $7(29.2)$ & $13(10)$ & 0.021 \\
\hline Anastomotic leakage & $1(4.2)$ & $6(4.6)$ & \\
\hline Pancreatic fistula & $4(16.6)$ & $3(2.3)$ & \\
\hline Intraabdominal infection & 0 & $2(1.5)$ & \\
\hline Pneumoia & $1(4.2)$ & 0 & \\
\hline Colitis & $1(4.2)$ & $1(0.8)$ & \\
\hline Incisional surgical site infection & 0 & $1(0.8)$ & \\
\hline \multicolumn{4}{|l|}{ Non-infectious complications } \\
\hline Total & $2(8.4)$ & $8(6.2)$ & 0.707 \\
\hline Lymphorrhea & 0 & $1(0.8)$ & \\
\hline Delayed gastric emptying & $1(4.2)$ & $2(1.5)$ & \\
\hline Ileus & $1(4.2)$ & $3(2.3)$ & \\
\hline Pleural effusion & 0 & $1(0.8)$ & \\
\hline Abdminal effusion & 0 & $1(0.8)$ & \\
\hline \multicolumn{4}{|l|}{$\begin{array}{l}\text { Hospital stay after } \\
\text { operation, days }\end{array}$} \\
\hline Median (range) & $12(8-46)$ & $11(6-57)$ & 0.23 \\
\hline
\end{tabular}

TG: Total gastrectomy, DG: distal gastrctomy, PG: proximal gastrectomy.

disease, and cancer. As a result, sarcopenia exerts various adverse effects, including malnutrition and immune depression. Several studies have reported sarcopenia to be associated with postoperative complications (2-9). However, the pathophysiological mechanisms underlying the association between preoperative sarcopenia and the risk of postoperative complications have not been elucidated. Luts et al. demonstrated that as skeletal muscle mass decreases and adipose tissue mass increases, the production of antiinflammatory cytokines and adiponectin decreases and the production of pro-inflammatory molecules, such as leptin, chemerin, resistin, tumor necrosis factor- $\alpha$, interleukin- 1 and -6 increases (24). Based on this mechanism, patients with sarcopenia are considered to be in a pro-inflammatory state. The pro-inflammatory state leads to a weakening of the immune system and poor wound healing after surgery, 
Table III. The risk factors for postoperative infectious complications for 153 patients after surgery for gastric cancer.

\begin{tabular}{|c|c|c|c|c|c|}
\hline \multirow[b]{2}{*}{ Variables } & \multirow[b]{2}{*}{ Comparison } & \multicolumn{2}{|c|}{ Univariate analysis } & \multicolumn{2}{|c|}{ Multivariate analysis } \\
\hline & & Odds ratio $(95.0 \% \mathrm{CI})$ & $p$-Value & Odds ratio $(95.0 \% \mathrm{CI})$ & $p$-Value \\
\hline Age & $\geq 75$ vs. $<75$ Years & $1.796(0.656-4.709)$ & 0.246 & & \\
\hline Gender & Male vs. female & $5.421(1.48-35.007)$ & 0.008 & $3.783(0.93-25.663)$ & 0.065 \\
\hline ASA PS & 3 vs. $1 / 2$ & $0.53(0.065-4.319)$ & 0.521 & & \\
\hline BMI & $\geq 25$ vs. $<25 \mathrm{~kg} / \mathrm{m}^{2}$ & $0.758(0.161-3.561)$ & 0.718 & & \\
\hline Serum albumin & $<3.5 v s . \geq 3.5 \mathrm{~g} / \mathrm{dl}$ & $2.275(0.733-7.062)$ & 0.175 & & \\
\hline Sarcopenia & Present $v s$. absent & $3.674(1.285-10.503)$ & 0.021 & $4.358(1.224-15.721)$ & 0.024 \\
\hline Surgical procedure & TG $v s$. DG, PG & $3.586(1.362-9.445)$ & 0.011 & $1.642(0.495-5.177)$ & 0.407 \\
\hline Surgical approach & Laparotomy vs. laparoscopy & $2.839(1.028-7.838)$ & 0.036 & $1.217(0.355-4.217)$ & 0.752 \\
\hline Operative time & $\geq 240 v s .<240 \mathrm{~min}$ & $1.233(0.473-3.212)$ & 0.667 & & \\
\hline Intraoperative blood loss & $\geq 400 v s .<400 \mathrm{ml}$ & $7.552(2.641-21.593)$ & $<0.001$ & $6.151(1.688-23.767)$ & 0.006 \\
\hline pStage & III/IV vs. I/II & $1.941(0.732-5.15)$ & 0.191 & & \\
\hline
\end{tabular}

TG: Total gastrectomy, DG: distal gastrectomy, PG: proximal gastrectomy.

thereby exerting an impact on the risk of postoperative complications (4). In our study, preoperative sarcopenia had an adverse effect on postoperative infectious complications (CD grade 2 or more) in patients with gastric cancer. In detail, in the group with sarcopenia, seven patients had infectious complications, four of them had pancreatic fistula. In addition, three out of the four patients with pancreatic fistula had bulky lymph node metastasis around the pancreas; in such patients in particular, tissue vulnerability tends to cause pancreatic damage, and it is thought that the weakening of the immune system and poor wound-healing may lead to pancreatic fistula.

Amino acids are essential elements for muscle synthesis. Muscle is a reservoir of amino acids, and when the body is subjected to invasion by surgery, muscle plays a role in distributing amino acids to each organ as a biological defense reaction (25). In patients with sarcopenia, however, the amount of amino acids available for tissue repair is insufficient. This mechanism is thought to cause delayed wound healing and further lead to infectious complications. Kim et al. demonstrated that the combination of lowintensity exercise and essential amino acid supplementation improved skeletal muscle mass, strength, and walking speed in sarcopenic women (26). However, the preoperative effects of nutrition therapy and resistance exercise on patients with gastric cancer have not been investigated to our knowledge. Preoperative nutritional intervention using amino acids and low-intensity exercise may contribute to reducing the incidence of postoperative complications. Further prospective intervention studies are needed to address this.

The present study is associated with several limitations. Firstly, the number of patients who were evaluated was small because the study was performed in a single institution. A large-scale, multi-institutional study is needed to validate our findings. Secondly, the EWGSOP evaluated sarcopenia based on skeletal muscle mass, while we evaluated sarcopenia based on whole-body muscle mass. Thirdly, according to the EWGSOP, sarcopenia is defined as the presence of low muscle mass, low muscle strength, and low muscle function. However, the definition of sarcopenia in our study was only based on muscle mass. A validation study with large sample size and an analysis of muscle strength and function is necessary to draw any definitive conclusions. Based on the results of retrospective studies, including our own, prospective studies including those that analyze the impact of intervention based on nutrition and resistance exercise should be performed.

\section{Conclusion}

Preoperative sarcopenia was found to be an independent risk factor for postoperative infectious complications in patients with gastric cancer. We, therefore, demonstrated that preoperative sarcopenia can be a predictor of postoperative infectious complications after the surgical treatment of gastric cancer.

\section{Conflicts of Interest}

The Authors declare no conflict of interest in regard to this study.

\section{References}

1 Cruz-Jentoft AJ, Baeyens JP, Bauer JM, Boirie Y, Cederholm T, Landi F, Martin FC, Michel JP, Rolland Y, Schneider SM, Topinkova E, Vandewoude M and Zamboni M: Sarcopenia: European consensus on definition and diagnosis - Report of the European Working Group on Sarcopenia in Older People. Age Ageing 39: 412-423, 2010. 
2 Voron T, Tselikas L, Pietrasz D, Pigneur F, Laurent A Compagnon P, Salloum C, Luciani A and Azoulay D: Sarcopenia impacts on short- and long-term results of hepatectomy for hepatocellular carcinoma. Ann Surg 261: 1173-1183, 2015.

3 Lieffers JR, Bathe OF, Fassbender K, Winget M and Baracos VE: Sarcopenia is associated with postoperative infection and delayed recovery from colorectal cancer resection surgery. Br J Cancer 107: 931-936, 2012.

4 Nishida Y, Kato Y, Kudo M, Aizawa H, Okubo S, Takahashi D, Nakayama Y, Kitaguchi K, Gotohda N, Takahashi S and Konishi M: Preoperative sarcopenia strongly influences the risk of postoperative pancreatic fistula formation after pancreaticoduodenectomy. J Gastroint Surg 20: 1586-1594, 2016.

5 Ida S, Watanabe M, Yoshida, Baba Y, Umezaki N, Harada K, Karashima R, Imamura Y, Iwagami S and Baba H: Sarcopenia is a predictor of postoperative respiratory complications in patients with esophageal cancer. Ann Surg Oncol 22: 4432-4437, 2015.

6 Nakashima Y, Saeki H, Nakanishi R, Sugiyama M, Kurashige J, Oki E and Maehara Y: Assessment of sarcopenia as a predictor of poor outcomes after esophagectomy in elderly patients with esophageal cancer. Ann Surg 267: 1100-110, 2018.

7 Joglekar S, Asghar A, Mott SL, Johnson BE, Button AM, Clark E and Mezhir JJ: Sarcopenia is an independent predictor of complications following pancreatectomy for adenocarcinoma. J Surg Oncol 111: 771-775, 2015.

8 Valero V 3rd, Amini N, Spolverato G, Weiss MJ, Hirose K, Dagher NN, Wolfgang CL, Cameron AA, Philosophe B, Kamel IR and Pawlik TM: Sarcopenia adversely impacts postoperative complications following resection or transplantation in patients with primary liver tumors. J Gastroint Surg 19: 272-281, 2015.

9 Peng PD, van Vledder MG, Tsai S, de Jong MC, Makary M, Ng J, Edil BH, Wolfgang CL, Schulick RD, Choti MA, Kamel I and Pawlik TM: Sarcopenia negatively impacts short-term outcomes in patients undergoing hepatic resection for colorectal liver metastasis. HPB 13: 439-446, 2011.

10 Tan BH, Birdsell LA, Martin L, Baracos VE and Fearon KC: Sarcopenia in an overweight or obese patient is an adverse prognostic factor in pancreatic cancer. Clin Cancer Res 15: 6973-6979, 2009.

11 Harimoto N, Shirabe K, YamashitaYI, Ikegami T, Yoshizumi T, Soejima Y, Ikeda T, Maehara Y, Nishie A and Yamanaka T: Sarcopenia as a predictor of prognosis in patients following hepatectomy for hepatocellular carcinoma. Br J Surg 100: 15231530,2013

12 Miyamoto Y, Baba Y, Sakamoto Y, Ohuchi M, Tokunaga R, Kurashige J, Hiyoshi Y, Iwagami S, Yoshida N, Yoshida M, Watanabe $\mathrm{M}$ and Baba H: Sarcopenia is a negative prognostic factor after curative resection of colorectal cancer. Ann Surg Oncol 22: 2663-2668, 2015.

13 Jaffrin MY and Morel H: Body fluid volumes measurements by impedance: A review of bioimpedance spectroscopy (BIS) and bioimpedance analysis (BIA) methods. Med Eng Phys 30: 12571269, 2008

$14 \mathrm{Kim} \mathrm{M}$ and Kim H: Accuracy of segmental multi-frequency bioelectrical impedance analysis for assessing whole-body and appendicular fat mass and lean soft tissue mass in frail women aged 75 years and older. Eur J Clin Nutr 67: 395-400, 2013.
15 Kaido T, Mori A, Ogura Y, Ogawa K, Hata K, Yoshizawa A, Yagi $S$ and Uemoto S: Pre- and perioperative factors affecting infection after living donor liver transplantation. Nutrition 28 : 1104-1108, 2012

16 Japanese Gastric Cancer Association: Japanese Classification of Gastric Carcinoma 2010. 14th ed. Tokyo Kanehara, 2010.

17 Janssen I, Heymsfield SB and Ross R: Low relative skeletal muscle mass (sarcopenia) in older persons is associated with functional impairment and physical disability. Journal of American Geriatrics Society 50: 889-896, 2002.

18 Japanese Gastric Cancer Association: Japanese gastric cancer treatment guidelines 2010 (ver.3). Gastric Cancer 14: 113-123, 2011.

19 Dindo D, Demartines N and Clavien PA: Classification of surgical complications: A new proposal with evaluation in a cohort of 6336 patients and results of a survey. Ann Surg 240: 205-213, 2004

20 Bassi C, Dervenis C, Butturini G, Fingerhut A, Yeo C, Izbicki J, Neoptolemos J, Sarr M, Traverso W, Buchler M; International Study Group on Pancreatic Fistula Definition: Postoperative pancreatic fistula: An International Study Group (ISGPF) definition. Surgery 138: 8-13, 2005.

21 Tokunaga M, Tanizawa Y, Bando E, Kawamura T and Terashima M: Poor survival rate in patients with postoperative intraabdominal infectious complications following curative gastrectomy for gastric cancer. Ann Surg Oncol 20: 1575-1583, 2013.

22 Mourtzakis M, Prado CM, Lieffers JR, Reiman T, McCargar LJ and Baracos VE: A practical and precise approach to quantification of body composition in cancer patients using computed tomography images acquired during routine care. Appl Physiol Nutr Metabol 33: 997-1006, 2008.

23 Kaido $\mathrm{T}$ and Uemoto S: Direct segmental multi-frequency bioelectrical impedance analysis is useful to evaluate sarcopenia. Am J Transplant 13: 2506-2507, 2013.

24 Lutz CT and Quinn LS: Sarcopenia, obesity, and natural killer cell immune senescence in aging: Altered cytokine levels as a common mechanism. Aging 4: 535-546, 2012.

25 Biolo G, Zorat F, Antonione R and Ciocchi B: Muscle glutamine depletion in the intensive care unit. Int J Biochem Cell Biol 37: 2169-2179, 2005.

26 Kim HK, Suzuki T, Saito K, Yoshida H, Kobayashi H, Kato H and Katayama M: Effects of exercise and amino acid supplementation on body composition and physical function in community-dwelling elderly Japanese sarcopenic women: A randomized controlled trial. J Am Geriatr Soc 60: 16-23, 2012.

Received December 14, 2018

Revised December 24, 2018

Accepted January 7, 2019 